\title{
Taking advantage of injustice
}

Erik Malmqvist

\section{Linköping University Post Print}

\section{Tweet}

N.B.: When citing this work, cite the original article.

Original Publication:

Erik Malmqvist, Taking advantage of injustice, 2013, Social Theory and Practice, (39), 4, 557-580.

http://dx.doi.org/10.5840/soctheorpract201339432

Copyright: Florida State University, Department of Philosophy http://www.fsu.edu/ philo/

Postprint available at: Linköping University Electronic Press

http://urn.kb.se/resolve?urn=urn:nbn:se:liu:diva-97258 


\title{
TAKING ADVANTAGE OF INJUSTICE
}

\begin{abstract}
What, if anything, is wrong with taking advantage of people's unjust circumstances when they both benefit from and consent to the exchange? The answer, some believe, is that such exchanges are wrongfully exploitative. I argue that this answer is incomplete at best, and elaborate a different one: to take advantage of injustice is to become complicit in its reproduction. I also argue that the case for third-party interference with mutually beneficial and consensual exchanges, while normally considered weak, is strengthened once these exchanges are understood as implicated in broader unjust structures.
\end{abstract}

\section{Introduction}

The prevailing liberal ethos prizes voluntary and mutually advantageous transactions and generally urges that they be protected from interference. Yet such transactions sometimes raise moral red flags. One sort of concern - the one I shall focus on in this paper - arises when one party takes advantage of an unjust situation to get the other party to agree to transact on her terms. What, if anything, is wrong with such advantage taking? And when, if ever, are third parties justified in preventing its occurrence? I shall argue that standard answers to these questions are incomplete at best. It is typically assumed that what is at stake is exploitation. But exploitation is only part of what might make such transactions wrongful; a distinct sort of wrong is more appropriately labeled complicity in injustice. Thus framing the issue is not just a question of theoretical accuracy but also has important practical implications.

My argument will proceed as follows. Section 2 presents three cases that illustrate the problem of taking advantage of injustice and distinguishes that problem from related issues of moral concern. Section 3 assesses the view that such advantage taking is 
wrongfully exploitative. Section 4 sketches a different view: to take advantage of injustices is to become implicated in their reproduction. In section 5 I shift focus from the ethics of twoparty exchanges to the ethics of third-party interference with such exchanges, arguing that the case for interference is strengthened once individual exchanges are understood as complicit in broader unjust structures. Section 6 sums up the results of my inquiry.

\section{Setting the stage}

The following cases illustrate the phenomenon explored in this paper.

Clinical Trial: B suffers from a serious but treatable disease. Because he is poor and lives in a country that doesn't provide its citizens with basic health care, he lacks access to effective treatment. Pharmaceutical company A wants to conduct a clinical trial of a new and promising treatment for B's condition. In order to reduce costs and get more convincing results A prefers to test the treatment against a placebo rather than against an existing active treatment. However, A predicts that a placebo-controlled trial wouldn't pass ethical review in a country where patients with the disease in question receive the existing treatment because it would require withholding that treatment from subjects who would otherwise get it. So it is decided to conduct the trial in B's country instead. When approached with the offer to participate in the trial, B accepts. He is fully aware of what participation entails. He knows that he will only have a $50 \%$ chance of receiving the experimental treatment, but figures that a 50-50 chance is better than no chance at all - the only alternative given his circumstances.

Sweatshop Labor: B is a small farmer in a poor country with a largely agrarian economy. International trade policies established by more powerful countries have made it increasingly difficult for farmers like B to sell their goods on the domestic and global markets. As a result, 
B can no longer rely on his plot of land to provide for his family. He lacks training for other available jobs and cannot expect aid from friends, family, or the state, so the situation looks grim. Then B learns that a newly established factory in a nearby town hires unskilled workers to produce running shoes for a multinational company. Eager for work B presents himself to $\mathrm{A}$, the local manager. $\mathrm{A}$ is quite frank: he is willing to hire $\mathrm{B}$, but the job involves hard work, long hours, and low pay. "Take it or leave it," A says. "If you're not interested there are many others who would happily take your place." Seeing no other way to earn an income, B accepts A's offer.

Domestic Work: B lives in a middle-income country where ethnic minorities, and especially their female members, face heavy discrimination. Because she is a minority woman, B is excluded both from most education and employment opportunities available to the majority and from most such opportunities available to minority men. However, as a single mother B needs whatever income she can get. She consequently finds herself moving between various temporary and poorly paid jobs. Right now B is out of luck: she has just been laid off and has no other job in sight. Relatively well off majority couple A proposes to hire B as a domestic servant for subsistence wage. B has no illusions about the job: she knows from previous experience that she will have to work hard, can expect little appreciation, and risks being fired on a whim. However, unwilling to turn down what she sees as the only decent way of feeding herself and her children, B accepts A's offer.

Analogous cases arise in a range of different contexts. ${ }^{1}$ Many feel uncomfortable about such cases, but it is difficult to pin down why. To be sure, poor people have often been harmed by

\footnotetext{
${ }^{1}$ People might not only choose to participate in clinical research or work in precarious conditions for low wages because these are the best options their constrained circumstances
} 
participating in clinical research, working in sweatshops, and (perhaps less clearly so) performing domestic work. But that isn't the case here. On the contrary, in each case B benefits from the transaction. Accepting A's offer makes B better off than they were before or would've been had they turned it down. There is a cost involved, of course, but the expected benefit makes the transaction all things considered advantageous to $\mathrm{B}$.

Nor does it seem that B fails to give valid consent to the exchange. In each case B understands what is on offer and is under no pressure from A to accept. Of course, B's circumstances are such that they accept the offer only because they lack other reasonable options. But it isn't clear that the lack of reasonable alternatives invalidates consent. ${ }^{2} \mathrm{~A}$ modification of Clinical Trial helps bring this out. Suppose B were offered the treatment for free without having to participate in the trial. Accepting the offer would still be B's only reasonable option, but we wouldn't question the validity of his consent.

admit; such circumstances might also lead them to sell a kidney, become prostitutes, agree to commercial surrogacy arrangements, and so on. See Janet Radcliffe-Richards, "Nephrarious Goings On: Kidney Sales and Moral Arguments," Journal of Medicine and Philosophy 21 (1996): 375-416; Martha C. Nussbaum, ““Whether from Reason or Prejudice’: Taking Money for Bodily Services,” Journal of Legal Studies 27 (1998): 693-724; and Alan Wertheimer, Exploitation (Princeton: Princeton University Press, 1996), chapter 4. While I believe that these latter activities raise precisely the issues I discuss in this paper, I shall leave them out of the discussion because they also raise other issues that would easily distract our attention. Kidney sales, prostitution, and commercial surrogacy are sometimes considered intrinsically objectionable, whereas work and participation in clinical research normally are not. ${ }^{2}$ Martin Wilkinson and Andrew Moore, “Inducement in Research,” Bioethics 11 (1997): 37389, p. 377. 
It seems, then, that we are dealing with mutually advantageous and consensual transactions. The question might be raised whether many real life cases are like these hypothetical ones. It could be argued that research participation, sweatshop labor, and domestic work do in fact typically harm poor people. Or it could be argued that when the poor pursue such options they are in fact typically coerced or deceived into doing so. Perhaps one or both of these claims are true. Much will depend on one's theory of harm or consent. But no reasonable theory would deny that some transactions relevantly similar to those our cases describe are both consensual and mutually beneficial. Regardless of how rarely such transactions occur we should be able to explain what is disturbing about them when they do occur.

I suspect that many people's unease is motivated by something like the following thought. The circumstances from which the exchanges arise are not merely unfortunate, but deeply unjust. B is unjustly denied access to basic health care in Clinical Trial, unjustly deprived of his livelihood in Sweatshop Labor, and unjustly excluded from education and better employment in Domestic Work. A benefits from these injustices, not by passively receiving gain from them, but rather by actively turning them into profit through interacting directly with B. More precisely, the perceptive observer might continue, A uses B's unjust circumstances to get B to agree to transact on terms that B wouldn't have accepted under just circumstances. While voluntary and mutually beneficial, their exchange either wouldn't have occurred or would have benefited B more, and A less, in a just world. In short, A takes advantage of injustice. Surely there is something objectionable about such conduct. ${ }^{3}$

\footnotetext{
${ }^{3}$ By focusing on actively turning injustice into profit, I set aside the distinct question whether passively receiving benefit from injustice also raises moral concern. See Norbert Anwander, "Contributing and Benefiting: Two Grounds for Duties to the Victims of Injustice," Ethics and International Affairs 19 (2005): 39-45.
} 
This is the line of reasoning I shall explore in this paper. To make any progress at all we must of course assume that B's situation is indeed unjust, and not merely unfortunate. This assumption is admittedly not beyond criticism in any of the cases. Nor is it particularly controversial, I think, but rather consistent with most plausible theories of justice. ${ }^{4}$

The problem of taking advantage of injustice should be distinguished from two other thorny issues surrounding cases of this sort. The problem arises regardless of one's views on these issues, and to keep my discussion focused I shall remain neutral on both of them. The first issue is whether A is responsible for B's plight prior to interacting with B. It might be argued that $\mathrm{A}$ isn't taking advantage of just any injustice, but of an injustice that $\mathrm{A}$ has helped create in the first place. Consider Clinical Trial. Pharmaceutical companies are arguably themselves responsible for the inadequate access to drugs that allows them to conduct placebo controlled rather than active controlled trials in developing countries. ${ }^{5}$ However, we should distinguish between the moral status of creating injustices and the moral status of taking advantage of injustices once they exist. Even if $\mathrm{A}$ is to blame for having caused B's plight in the first place, we still need to ask whether and why A deserves additional blame for then seeking to profit from B's plight.

\footnotetext{
${ }^{4}$ For an extensive defense of the claim that the background conditions obtaining in cases like Sweatshop Labor and Clinical Trial are unjust on most theories of justice, see Thomas Pogge, World Poverty and Human Rights, $2^{\text {nd }}$ ed. (Cambridge: Polity Press, 2008). As to Domestic Work, I suspect few would disagree that overt ethnic and sexual discrimination in education and the labor market is unjust.

${ }^{5}$ Thomas Pogge, "Testing Our Drugs on the Poor Abroad," in Jennifer S. Hawkins and Ezekiel J. Emanuel (eds.), Exploitation and Developing Countries: The Ethics of Clinical Research (Princeton: Princeton University Press, 2008), pp. 105-41.
} 
The second issue is whether A has a positive duty to aid B. It might be argued that while A hasn't caused B's plight, A is nonetheless obligated to help B given the precariousness of B's situation. After all, most agree that there is a general duty to help the desperately needy when one can do so easily and at little personal cost. ${ }^{6}$ If A has such a duty to B in our cases, then A clearly acts wrongly. If A is obligated to give B an effective treatment (Clinical Trial) or help secure B's subsistence (Sweatshop Labor and Domestic Work), A cannot ask for anything in return from B for these benefits. Instead, A should confer them "free of charge". But even if we think that A has such a duty, and that taking advantage of B therefore is wrong, we need to know more about the nature of that wrong. For taking advantage of victims of injustice is just one way of violating a duty to aid them. Another way is to simply ignore their plight. Proponents of the duty to aid should ask themselves which transgression is worse and why. Whether or not there is such a duty, then, the problem of taking advantage of injustice remains.

\section{Exploitation}

Our question is this: what is wrong with taking advantage of injustice when those taken advantage of both benefit and consent? It is sometimes suggested that such behavior is wrongfully exploitative. Exploitation is commonly considered capable of occurring even

\footnotetext{
${ }^{6}$ For a classic defense of a demanding version of this view, see Peter Singer, "Famine, Affluence, and Morality," Philosophy and Public Affairs 1 (1972): 229-43. For a less demanding version applied to the context of international clinical research, see Jennifer S. Hawkins, “Justice and Placebo Controls,” Social Theory and Practice 33 (2006): 467-96.
} 
within mutually advantageous and voluntary exchanges, ${ }^{7}$ so this suggestion has considerable initial appeal. In this section I assess whether it is ultimately convincing.

To exploit a person, in a morally pejorative sense, is to take advantage of her in some wrongful way. While moral and political philosophers agree on this very broad characterization, they don't agree at all about how to specify the key notions "take advantage of" and "wrongful”. Reflecting such fundamental disagreement, there is also little agreement as to what role background injustices should play in classifying transactions as exploitative.

According to the now seemingly dominant group of theories they shouldn't play much of a role at all. These theories consider transactions exploitative when they distribute benefits and burdens unfairly. On Alan Wertheimer's celebrated account, for instance, A exploits B when A takes unfair advantage of B - more precisely, when A leaves B with an unfairly small share of the fruits of their exchange. ${ }^{8}$ Similarly, Robert Mayer defines exploitation as a "failure to benefit a disadvantaged party as fairness requires". ${ }^{9}$ Both theories are compatible with different standards of fairness and may thus lead to very different judgments as to which particular transactions are exploitative. They would therefore not necessarily conclude that our cases involve exploitation; that depends on what standard of

\footnotetext{
${ }^{7}$ See e.g. Wertheimer, Exploitation; Joel Feinberg, Harmless Wrongdoing (Oxford: Oxford University Press, 1990); Allen W. Wood, “Exploitation,” Social Philosophy and Policy 12 (1995): 136-58; Ruth Sample, Exploitation: What It Is and Why It's Wrong (Lanhamn, MD: Rowman \& Littlefield, 2003); and Robert Mayer, "What's Wrong with Exploitation?" Journal of Applied Philosophy 24 (2007): 137-50. Some disagree; see Stephen Wilkinson, Bodies for Sale: Ethics and Exploitation in the Human Body Trade (London: Routledge, 2003).

${ }^{8}$ Wertheimer, Exploitation.

${ }^{9}$ Mayer, "What's Wrong with Exploitation," p. 143.
} 
fairness one applies. ${ }^{10}$ But if they would, this is how the argument would go. B is exploited because she doesn't receive all that she can expect from the transaction as a matter of fairness. A owes B more. To avoid exploitation, A must offer, for instance, a better chance of receiving effective treatment in Clinical Trial, or a higher wage and better working conditions in Sweatshop Labor and Domestic Work.

What is salient for present purposes is that these fairness-oriented theories regard exploitation as transaction specific. Whether an exchange is exploitative depends solely on the terms of that exchange. It does not depend on any feature of the broader social, economic, or political context in which the exchange occurs. The fact that B's background conditions are unjust, for instance, has no bearing on whether A exploits B. Perhaps she does, but it all comes down to what each party can expect to receive from their exchange.

The transaction specific view on exploitation might seem too lenient on exchanges arising from unjust circumstances. Shouldn't the fact that B is the victim of injustice at all affect our evaluation of A's conduct? Many think that it should, and I agree. There are, generally speaking, two ways in which one might develop that thought. The relevance of background injustice to the morality of individual exchanges might be conceptualized within exploitation theory, by abandoning or amending the transaction specific view, or independently of exploitation theory. While the first strategy is more familiar, I shall (in section 4) pursue the second one. Note that these strategies are not

${ }^{10}$ Indeed, Wertheimer doubts that cases like Clinical Trial involve exploitation. See Alan Wertheimer, Rethinking the Ethics of Clinical Research: Widening the Lens (Oxford: Oxford University Press, 2011), pp. 224-32. Mayer, on the other hand, discusses sweatshop labor as an example of failing to benefit another as fairness requires. See Mayer, "What's Wrong with Exploitation?” pp. 141-42; and Mayer, “Sweatshops, Exploitation, and Moral Responsibility," Journal of Social Philosophy 38 (2007): 605-19. 
incompatible: taking advantage of injustice might be both wrongfully exploitative and wrong on other grounds. So whether or not the first strategy succeeds there is reason to consider the second one. Still, we should begin by examining the first strategy. For if, as I suspect, that strategy fails - if exploitation theory doesn't adequately explain the wrongness of taking advantage of injustice - my alternative account takes on additional importance.

Critics of the transaction specific view hold that we cannot disregard the context in which transactions occur when assessing whether they are exploitative. In particular, we cannot disregard injustices in the background conditions from which the transactions arise. Essential to at least some forms of exploitative exchange is the fact that they prey on preexisting unjust social arrangements. ${ }^{11}$ What raises concern about exploitation in our cases is not (only) how B can expect to fare as a result of the exchange, but (also) the wretched circumstances that make B agree to it.

I doubt that the connection between exploitation and background injustice is quite as tight as the critics contend. As several authors have noted, taking advantage of injustice seems neither necessary nor sufficient to render transactions exploitative. ${ }^{12}$ That it isn't necessary can be shown by removing the background injustices from our cases while leaving them otherwise intact. In Domestic Work B agrees to work for A because she lacks other options. Now suppose that this lack of options doesn't reflect discrimination, but instead

${ }^{11}$ Sample, Exploitation; John E. Roemer, Free to Lose: An Introduction to Marxist Economic Philosophy (London: Radius, 1988); and Jeremy Snyder, ’Exploitations and their Complications: The Necessity of Identifying the Multiple Forms of Exploitation in Pharmaceutical Trials," Bioethics 26 (2012): 251-58.

\footnotetext{
${ }^{12}$ Wertheimer, Exploitation; Mikhail Valdman, "Exploitation and Injustice," Social Theory and Practice 34 (2008): 551-72; and Matt Zwolinski, "Structural Exploitation," Social
} Philosophy and Policy 29 (2012): 154-79. 
B's voluntary choices or simply bad luck. Suppose, for instance, that B has no other option because she has passed up worthwhile education opportunities made available to her (voluntary choice), or because there is a high - but, let's assume, not unjust - unemployment rate (bad luck). And suppose also that the terms that A proposes and B accepts are the same: hard work, low pay, no security. If we found the exchange as initially described exploitative, should we now revise that judgment? I don't think we should.

Changing Sweatshop Labor in an analogous way illustrates the same point. Suppose that B has been left without livelihood not because of trade agreements forced upon his country by more powerful nations (injustice), but because his land has been lost through gambling (voluntary choice) or destroyed in a freak fire (bad luck). ${ }^{13}$ Should we worry less about exploitation if B accepts to work in sweatshop conditions for either of these reasons? Again, I don't think we should. In neither case do our concerns about exploitation seem to turn on whether B is the victim of injustice, for these concerns remain if we imagine that B is instead the victim of bad luck or their own imprudence. ${ }^{14}$

While not necessary for exploitation, it might still be argued that taking advantage of injustice is sufficient to render transactions exploitative. Ruth Sample holds this view. She writes: "If we gain advantage from an interaction with another, and that advantage is due in part to an injustice he has suffered, we have failed to give him appropriate respect". ${ }^{\prime}$

\footnotetext{
${ }^{13}$ We must assume, of course, that B's vulnerability to accidental fires isn't itself rooted in injustice. This assumption might not hold, for instance, if B is unable to obtain insurance due to unjust poverty.

${ }^{14}$ The argument in this paragraph and the preceding one is inspired by Mikhail Valdman's lengthier and more sophisticated argument to the same effect. See Valdman, "Exploitation and Injustice,” pp. 554-55.

${ }^{15}$ Sample, Exploitation, p. 74.
} 
And, on her theory, failing to respect others when we seek to benefit from interacting with them constitutes exploitation.

The view that taking advantage of injustice suffices for exploitation might seem easy enough to dismiss. Wertheimer offers the following counter-example:

Unjust Firing: B has been unjustly fired from a law firm where she was making $\$ 150,000$ per year. A community college offers her a position to teach law courses for $\$ 40,000$ per year, the maximum salary that it can offer. ${ }^{16}$

Here A (the community college) appears to take advantage of an injustice done to B. However, assuming (as Wertheimer seems to do) that $\$ 40,000$ per year is a passable salary for the job in question, it seems far-fetched to say that A wrongs B. In particular, B couldn't plausibly claim that A exploits her: "B's complaint is the law firm, not the community college." 17

This dismissal strikes me as too quick. There is arguably a difference between taking advantage of single instances of unjust treatment and taking advantage of structural injustices. ${ }^{18}$ In Unjust Firing, A profits from a one-off injustice that B has already suffered at

${ }^{16}$ Wertheimer, Rethinking the Ethics of Clinical Research, p. 208.

${ }^{17}$ Ibid. Similarly, Matt Zwolinski remarks that "someone who performs a useful service at a fair price for victims of injustice does not wrongfully exploit them". See Zwolinski, “Structural Exploitation," p. 172. For a more extreme example in the same vein, see Valdman, “Exploitation and Injustice,” pp. 559-60.

${ }^{18}$ For more on the notion of structural injustice, see Iris Marion Young, Responsibility for Justice (Oxford: Oxford University Press, 2011), pp. 45-64. While I use the term in a way 
the hands of another. By contrast, in Clinical Trial, Sweatshop Labor, and Domestic Work, A profits from a much broader and ongoing unjust distribution of fundamental goods and opportunities. This latter form of advantage taking might seem worse. This suggests that we should focus specifically on structural injustices when assessing whether taking advantage of injustice is sufficient for exploitation.

But even when structural injustices are taken advantage of the charge exploitation sometimes appears strained. Imagine Domestic Work develops as follows:

Concerned Neighbor: C, a woman in A's neighborhood, learns about how A treat B and is deeply concerned. She thinks B is paid too little and works too hard, and she genuinely wants to help. But $\mathrm{C}$ is also elderly and needs assistance with daily household tasks and with caring for her sick husband. Lacking a family willing to help, she proposes to hire B for the job. At first B is reluctant: she would have to quit working for $\mathrm{A}$ to adequately assist $\mathrm{C}$ and wants to make sure that $\mathrm{C}$ really offers a better deal. $\mathrm{C}$ explains that $\mathrm{B}$ would be expected to work considerably less than at A's house and would enjoy a more convenient schedule. C also proposes to pay more. But because she isn't as well off as A and her husband has considerable medical expenses, she cannot afford more than a modest wage increase. B is aware that a majority woman probably wouldn't feel compelled to accept such an offer. But she also realizes that it represents a clear improvement over working for A. Consequently, B accepts C's proposal.

Here $\mathrm{C}$ takes advantage of a structural injustice. If $\mathrm{B}$ had fair access to education and the labor market, she would have other ways of securing her subsistence than working on either A's or

roughly following Young's usage, I disagree (as explained below) with some of her substantive claims about responsibility for such injustice. 
C's terms. She would be able to demand higher pay and better conditions in return for her domestic services, or seek some different kind of employment. C uses B's unjust situation to obtain B's agreement to an exchange that B wouldn't have accepted in a just world.

But does $\mathrm{C}$ exploit B? While it might be claimed that she does, I am inclined to think otherwise. Surely the point with calling $\mathrm{C}$ an exploiter is to say she wrongs B in some non-trivial way. But $\mathrm{C}$ does much to help $\mathrm{B}$, much more than anyone else is prepared to do. Moreover, C could easily use B's situation to secure a better deal for herself at B's expense (by offering a lower wage, say, or demanding longer days). In fact, $\mathrm{C}$ appears to do the best she can for B given her own constrained situation. Contrast this with our introductory cases, where A could benefit B more without seriously compromising their own welfare, but choose not to. Here the charge of exploitation appears more appropriate. ${ }^{19}$ I am not suggesting that C's conduct is completely morally innocent in Concerned Neighbor, only that it doesn't seem rightly labeled exploitative. If I am right about this, then taking advantage of injustice - even structural injustice - is insufficient for exploitation.

To conclude, the transaction specific view seems correct about the relationship between exploitation and background injustice. We should look at outcome rather than

\footnotetext{
${ }^{19}$ It might be argued Concerned Neighbor involves exploitation, but of a different kind than our other cases. Mayer distinguishes between “discretionary exploitation”, where A could offer B fair terms but choose to offer unfair terms instead, and "structural exploitation", where A cannot offer B better terms because of the constraints they face. See Mayer, "Sweatshops, Exploitation, and Moral Responsibility”. There is certainly an important distinction between these types of exchange, but I am not convinced that the latter should be labeled exploitation. As I see it, "[e]xploitation is tied to the set of feasible options available to A". See Wertheimer, Rethinking the Ethics of Clinical Research, p. 209. As suggested below, complicity seems like a better label.
} 
context when assessing whether an exchange is exploitative. This is not to deny that many exchanges arising from structural injustice are in fact exploitative. It seems highly likely that such injustices often weaken people's bargaining position up to the point where it is difficult for them to turn down unfair offers. Indeed, I believe that Clinical Trial, Sweatshop Labor, and Domestic Work illustrate precisely this phenomenon. But it isn't the underlying injustice in itself that makes such exchanges exploitative. After all, people can have their bargaining position weakened also by perfectly just background conditions. We should distinguish the claim that exploitation and structural injustice tend to coexist from the claim that they are conceptually connected.

Also, to deny that background injustices in themselves make exchanges exploitative is not to deny their relevance to the morality of these exchanges altogether. The fact that it is an injustice - and not just any weakness - that A take advantage of in our cases does, I believe, matter to our evaluation of their conduct. I thus disagree with Wertheimer's claim that "even when B's suffering is rooted in social injustice, it may (reasonably) be treated as a misfortune by A, if A bears no special responsibility for causing or alleviating B's suffering". ${ }^{20}$ B's suffering can be regarded as a misfortune as far as exploitation goes, as this section has tried to show. However, it cannot be regarded as a misfortune if we want a global moral assessment of the transaction between A and B. By taking advantage of unjust suffering, A becomes complicit in injustice. Or so I shall argue in the next section.

\section{Complicity}

Turning other people's unjust circumstances into profit for oneself isn't morally innocent, even if they consent to and benefit from the exchange. Exploitative or not, such behavior raises another, less familiar concern, which I shall now explore. To take advantage of

\footnotetext{
${ }^{20}$ Wertheimer, Exploitation, p. 298.
} 
structural injustices, in the way A does in our introductory cases, is to become implicated in their perpetuation. One becomes, in a word, complicit. Exploitation and complicity often occur together, but it is important to distinguish them. For only from the standpoint of complicity can we see why it matters that it is an unjust, rather than a tough but fair, situation that is taken advantage of.

Shifting focus from exploitation to complicity broadens the scope of our inquiry. If A exploits B then A wrongs B. By contrast, if their interaction makes A complicit in the unjust background circumstances, then A commits a wrong suffered by a much larger group: those disadvantaged by these circumstances more generally. But note that I focus on A's conduct. I thus bracket the even broader question whether, as citizens in affluent democracies or consumers in a global economy, we are all implicated in the reproduction of structural injustice. ${ }^{21}$ We may very well be, but I am interested in the specific form of implication created by advantage taking behavior such as A's.

\section{a) The concept of complicity}

Following Christopher Kutz's influential treatment of the topic, I shall understand being complicit as bearing a relation to some collectively caused harm by virtue of which one is accountable for that harm. ${ }^{22}$ To be accountable is to warrant a response of some sort or other from different parties: victims, bystanders, oneself, other implicated agents, and possibly the law. Often it is clearly morally wrong to be complicit, for instance if one lends a gun to an obvious potential killer. Appropriate responses are then guilt on one's own part, resentment on the part of the victims, and blame on the part of third parties. But sometimes it is debatable

\footnotetext{
${ }^{21}$ See Pogge, World Poverty and Human Rights; and Young, Responsibility for Justice.

${ }^{22}$ Christopher Kutz, Complicity: Ethics and Law for a Collective Age (Cambridge:

Cambridge University Press, 2000).
} 
whether complicity is even pro tanto wrongful, for instance if one works in a factory producing metal bolts, some of which are sold to the military industry and used for building tanks later employed in a destructive war. But responses may be warranted nonetheless. One may appropriately feel and be expected to express special sympathy and regret for the plight of the war victims. To keep things simple, I shall assume that complicity in injustice constitutes a wrong - albeit sometimes a minor, easily outweighable one.

Philosophers disagree about the ultimate grounds of complicity. Law and morality alike often hold people accountable on causal grounds. I may be prosecuted for facilitating someone else's crime, or morally reproached because I encourage someone else to lie or cheat. Some regard causality as the only basis for complicity. ${ }^{23}$ However, Kutz insists that all forms of complicity cannot be reduced to one single type of relation. His main contribution is an intentional approach, according to which individuals are accountable for harms resulting from collective endeavors in which they intentionally participate. But he also suggests that complicity can be character-based: individuals can be linked to harms through their commitments and affiliations. While I have no objections to such a pluralistic view on a general level, I will focus on the causal approach for the purposes of this paper. How somebody can become complicit in injustice by taking advantage of it seems best explained in causal terms. To see why, let us briefly consider the two other approaches.

\section{b) Intentional participation}

A major attraction of the intentional approach is that it appears to handle cases of causal overdetermination better that the causal approach. Consider Kutz's favorite example: the Allied bombing of Dresden during World War II, which produced a firestorm that killed tens

\footnotetext{
${ }^{23}$ John Gardner, "Complicity and Causality," Criminal Law and Philosophy 1 (2007): 127-
} 140. 
of thousands of civilians. Large numbers of individuals - pilots, bombers, gunners, planners, and so on - were involved in the bombing. Many (including some actual participants) have regarded all these individuals as in some sense accountable for the resulting mayhem. Yet most didn't make a causal difference; the firestorm would've been equally destructive had any one of them opted out. All involved were nonetheless accountable for the destruction, Kutz argues, because all participated intentionally in the collective activity that caused it. ${ }^{24}$ People act together when each one conceives of his or her action as furthering a shared end and their respective conceptions overlap sufficiently. Each one is then accountable for everyone else's actions and for the consequences of their joint project regardless of whether he or she contributes causally to or intends these actions or consequences.

One difficulty with using this approach for present purposes is that structural injustices often aren't the result of any joint project, but instead of uncoordinated actions of large numbers of agents each pursuing their individual interest. ${ }^{25}$ More importantly, even when structural injustices are the result of joint projects, as surely they sometimes are, many of those who take advantage of these injustices don't participate in these projects. In Sweatshop Labor, for instance, B loses his livelihood because of deliberate and coordinated international trade policies established by affluent countries. However, A hardly identifies himself as acting together with the makers of these policies, but rather opportunistically capitalizes on their effects. So A isn't complicit on intentional grounds.

\section{c) Complicity and character}

The character-based approach doesn't seem any better suited for explaining how one might become complicit in structural injustices by taking advantage of them. Kutz thinks of

\footnotetext{
${ }^{24}$ Kutz, Complicity, pp. 121-22, 137-44.

${ }^{25}$ Young, Responsibility for Justice, p. 102.
} 
character-based complicity in counterfactual terms: "Agents are accountable not only by virtue of what they have done or caused, but for what they might have done or caused. They are accountable in virtue of who they are. ${ }^{, 26}$ Individuals who aren't themselves involved (causally or intentionally) in producing a wrong can nonetheless be accountable for the wrong because they could've been involved in other circumstances. They are the sort of people who don't shun involvement in wrongdoing.

I suppose we could hold A accountable for B's unjust circumstances on such counterfactual grounds in our cases. We might suspect that A could've played a role in creating these circumstances, even if in this case she actually didn't. However, that judgment doesn't hinge on the fact that A takes advantage of these circumstances. If A is the sort of person who might become involved in producing injustice, she is that sort of person regardless of what she does in any particular case. At most, A's behavior towards B plays an evidentiary role: it allows us to infer what sort of person she is.

\section{d) Causal complicity}

We are left, then, with the causal approach, which considers individuals accountable for harms to the extent that they contribute causally to them. Returning to our cases, can A be regarded as complicit, in such a causal sense, in the structural injustices that they take advantage of when interacting with B? I believe they can.

Now the causal approach faces an important challenge that needs to be tackled before proceeding further. Like many other collective harms, structural injustices tend to be produced by causal mechanisms that are highly complex and difficult to survey. The causal basis for holding individuals accountable for such injustices may therefore seem weak. Three more specific concerns need to be distinguished here. First, it is reasonable to think that many

\footnotetext{
${ }^{26}$ Kutz, Complicity, p. 190.
} 
structural injustices are caused by multitudes of marginal individual contributions, much like global warming is caused by multitudes of individuals and enterprises whose emissions each contributes only marginally to the overall problem. Second, many structural injustices are arguably causally overdetermined. Each single plane was superfluous in producing the Dresden firestorm, Kutz suggests, because the bombs from the other planes were more than enough to ignite it. A may seem equally superfluous in perpetuating the unjust structures they take advantage of because so many others also take advantage of them. The upshot of both concerns is this: it seems inappropriate to hold individuals accountable on causal grounds for harms to which they make no significant causal difference. ${ }^{27}$ The third concern is that even if individuals do make a difference to structural injustices, it seems inappropriate to hold them accountable because their respective contributions are likely difficult to ascertain. ${ }^{28}$

Different responses to such concerns are possible. ${ }^{29}$ A simple but, for present purposes, effective one is that A's behavior should be assessed from an ex ante rather than an ex post perspective. People are often held accountable for risking harm even when no harm actually ensues. Speeding past a school is rightly sanctioned, both legally and morally, even if no child ends up harmed or killed. The driver's recklessness turns out to be harmless but condemns him nonetheless. Drawing on this rationale, Larry May argues that those who recklessly take risks without causing harm share responsibility for harms caused by others who take similar risks:

${ }^{27}$ For extensive discussion of both these difficulties with the causal model, see Kutz, Complicity, pp. 115-29, 168-75.

${ }^{28}$ Young, Responsibility for Justice, pp. 96, 109.

${ }^{29}$ Gardner, "Complicity and Causality”; Larry May, Sharing Responsibility (Chicago: University of Chicago Press, 1992). 
Consider ... the case of two people, each of whom does not remove the snow from his or her portion of a common sidewalk, although each knows that harm to delivery people and others is risked. The first person's omission actually results in an accident on his portion of the sidewalk; the second person's omission does not result in harm. If both displayed the same knowledgeability and lack of due care, then the first person is unlucky and the second is lucky ... From a moral perspective ... both people have engaged in risky omissions, and the fact that one of them was unlucky does not seem relevant. ${ }^{30}$

This approach helps address concerns about causal overdetermination. Perhaps the individual pilot didn't end up contributing to the devastation of Dresden, but when he first set out on the mission it was surely likely that he would contribute. Despite his actual causal inefficacy, which was essentially due to luck, the pilot shares responsibility because of the riskiness of his conduct. Similarly, if A engages in behavior that collectively reproduces structural injustice he is implicated in that injustice insofar as ex ante he risks contributing to it, even if ex post he turns out to be lucky enough to have made no actual difference.

Concerns about the inascertainability of individual contributions can be addressed in a similar way. Ex ante attributions of responsibility for risky conduct do not seem to require that we identify an agent's precise causal relationship to a very specific harm. Suppose a group of workers operating heavy and complex machinery decide to get drunk on the job. We consider each of them responsible for their recklessness because we have some general idea of the sorts of harm that might occur in their line of work and of the effects of alcohol on people's behavior. No full account of the causal role of each one in some very clearly defined accident is needed to make that judgment. Nor is such an account needed for

\footnotetext{
${ }^{30}$ May, Sharing Responsibility, p. 44.
} 
holding A accountable for risking contributing to the injustices they take advantage of. What is required is some general conception, of the sort developed below, of the role of such conduct in the reproduction of these injustices.

What about the concern about marginal contributions? Adopting an ex ante perspective allows for at least a partial response here too. From such a perspective, it will often be uncertain whether an individual contribution to a collective harm will be marginal or substantial. One factory's emissions may or may not end up significantly influencing the already poor air quality in a heavily industrialized area; either way, the manager arguably shares responsibility for the unhealthy air because he risks having an influence. ${ }^{31}$

But there is another and perhaps better response. Given the vastness of the structures A profit from, it appears that A's impact on these structures, considered in their entirety, can only be negligible. However, it is unclear that we should adopt such a broad view. Structural injustices are indeed very general scourges, but in the final analysis they are constituted by individual agents acting in response to structural constraints and possibilities, thereby constraining and enabling others. ${ }^{32}$ The impact of single exchanges may appear miniscule when seen from the perspective of overall structures, but not when seen from the individual level where structures are reproduced. In Domestic Work, for instance, A are highly unlikely to make much difference to the extent of racial and sexual discrimination in their country as a whole, but less unlikely to contribute to discriminatory attitudes and

\footnotetext{
${ }^{31}$ A distinct point is that small contributions could sometimes tip the balance toward the occurrence of some harm that otherwise wouldn't occur at all. See Gardner, "Complicity and Causality," p. 138.

${ }^{32}$ Young, Responsibility for Justice, pp. 53-56, 59-62; Jeffrey Reiman, “The Structure of Structural Injustice: Thoughts on Iris Marion Young's Responsibility for Justice," Social
} Theory and Practice 38 (2012): 738-51. 
practices more locally. Including the local view strengthens the causal basis for complicity. The analogy to global warming is potentially misleading in this respect. One can contribute to the harms caused by global warming only by making a difference to that phenomenon as a whole. No local view applies here.

So the complexity and opacity of the processes causing structural injustice notwithstanding, there is room for a causal model of complicity. Individuals can become complicit in injustices they take advantage of by risking contributing causally to them. However, the question remains just how they might contribute. Generally speaking, there are at least two ways to do so. First, taking advantage of injustice might create or reinforce incentives to maintain rather than change the unjust status quo. Remember that we are dealing with mutually advantageous transactions. Because A benefits from an exchange that either wouldn't occur or would benefit A less in just circumstances, he is unlikely to want to see such circumstances realized. In fact, A has reason to actively oppose change, at least if he can do so effectively and the benefit at stake is large enough.

It might be objected that we should distinguish more carefully between two different acts. While opposing reform is clearly wrongful and taking advantage of injustice creates incentives for such opposition, it doesn't follow, the objection goes, that such advantage taking is also wrongful. Why should giving oneself a reason to engage in wrongdoing be blameworthy if one can later choose not to act on that reason? I have two responses. First, in Clinical Trial and Sweatshop Labor, A represents an organization that stands to gain as a whole. While it is an individual A who negotiates with B, any power to effectively oppose reform is likely to be in the hands of other members of the organization. A is then strictly speaking motivating someone else to oppose reform. In this respect, A is like somebody who hires a killer whose deeds she cannot later avert. Both create a reason for wrongdoing the subsequent commission of which they cannot influence. Second, it isn't clear 
that creating reasons for wrongdoing is innocent in strictly individual cases either. Putting oneself in a position where one foresees, or should foresee, to find it difficult to resist acting wrongly is arguably itself blameworthy whether or not one later proves capable of resisting.

Perhaps somewhat more surprisingly, the transaction might make B, too, less likely to strive for change inasmuch as it makes the status quo more tolerable. For B himself such acceptance is most likely a price well worth paying for the benefit on offer. Accepting A's proposal is, after all, B's best option given his constrained circumstances; I do not mean to trivialize this fact. However, B's acceptance of the status quo may undercut the attempts of other victims of injustice to collectively achieve a more just state of affairs. So while the individual B benefits the class of B's stands to lose. And in the long run even the individual B might risk losing if he has more to gain from organized change than from the transaction.

Further, it is worth noting that many mutually advantageous transactions also benefit third parties. When such transactions presuppose an unjust status quo, they give these third parties reason to oppose change. Consider Clinical Trial, where future patients stand to gain from a new and potentially better treatment and the host community from job opportunities and improved care infrastructure at the trial site, among other things. ${ }^{33}$ These benefits are by no means trivial, and policy makers eager to secure them may be reluctant to change the circumstances from which they flow. Host countries may be less willing to improve health care for their citizens if that makes pharmaceutical companies take their favorable business elsewhere. And affluent countries may not want to help improve health care in poor countries if that undercuts the development of drugs for their own patients. The general point is this: by taking advantage of B's unjust circumstances, A might give others reason not to correct these circumstances.

${ }^{33}$ Adriana Petryna, When Experiments Travel: Clinical Trials and the Global Search for Human Subjects (Princeton: Princeton University Press, 2009). 
A second way to contribute to structural injustice by taking advantage of it is through the expressive meaning of one's action. Now what actions express tends to be ambiguous, and care must be taken to avoid overly strained interpretations. But there is at least one interpretation that seems quite straightforward. By turning structural injustice into personal gain one signals that such conduct is morally permissible. ${ }^{34}$ One thereby contributes to legitimizing similar advantage taking on the part of others similarly placed. By hiring B for subsistence wage in Domestic Work, for instance, A might send the message to (say) their friends and neighbors that they too may legitimately hire unemployed minority women for subsistence wage. That is, A encourages others to enter into exchanges that, as argued above, risk reinforcing incentives to resist structural reform.

In addition to this fairly obvious message, agents who take advantage of injustice also arguably send another one, subtler but no less worrisome. Note that A interacts directly with B in all our cases. In an important sense, A therefore comes face to face with injustice. B lacks something that she is entitled to and that A possesses, but that - so the terms of the transaction stipulate - A isn't going to give her for free. Now it might not be A's duty to repair B's unjust circumstances; I have deliberately left that question open. But somebody has such a duty. It doesn't seem too far-fetched to think that by deliberately not repairing B's circumstances, A sends the message that those who ought to repair them may neglect doing so as well. Consider Clinical Trial again: by deliberately withholding medical treatment to which B is entitled, A might suggest that those who should secure that treatment (the state, perhaps, or the international community) may continue withholding it as well. In this sense, A contributes to the continuing neglect of injustice.

A might respond that they in fact deplore the circumstances that lead B to transact and have no intention to encourage passivity on the part of those responsible for

\footnotetext{
${ }^{34}$ For a similar point, see Anwander, "Contributing and Benefiting,” p. 43.
} 
repair. However, the meaning of one's actions doesn't flow straight from one's own

intentions or beliefs, but is partly constituted by the recipient and the broader context. ${ }^{35}$ So A may well end up entrenching tolerance for B's unjust situation without wanting or intending to, making that situation less likely to change.

\section{e) Avoiding, justifying, and compensating for complicity}

I have said that complicity is a pro tanto wrong. As such it should be avoided, other things being equal. Perhaps the possibility of taking advantage of structural injustices without becoming complicit shouldn't be excluded altogether. Certain isolated exchanges arising from such injustices might be too brief to create any lasting incentive to maintain them and too private to communicate tolerance for them to anyone else. However, even very brief and private exchanges may contribute, if only slightly, to normalizing broader practices, and vast numbers of exchanges - such as those our cases depict - are in fact public and extended in time. Here one can avoid complicity only by refraining from taking advantage of injustice. This requires interacting on terms that the other would accept if background conditions were just. More concretely, avoiding complicity in Clinical Trial requires designing the study so that $\mathrm{B}$ might consider participating even if he had access to treatment - that is, testing against that treatment instead of placebo. In our other cases it requires offering a wage and working conditions that B would accept if he still had the option of living off his land (Sweatshop Labor), or if she had fair access to education and the job market (Domestic Work). ${ }^{36}$

\footnotetext{
${ }^{35}$ This observation is familiar to Wittgensteinians and phenomenologists. See Lisa Folkmarsson Käll, “Expression between Self and Other,” Idealistic Studies 39 (2009): 71-86. ${ }^{36}$ For an essentially identical account of what avoiding taking advantage of injustice requires, see Pogge, "Testing Our Drugs on the Poor Abroad," p. 113. While Pogge claims that such
} 
Of course, other things aren’t always equal. Individuals and organizations may find themselves constrained in ways that make non-complicit interaction practically impossible, prohibitively demanding, or unreconcilable with more stringent moral requirements. In Sweatshop Labor, for instance, A might claim that he operates on the margin and simply cannot offer a wage and working conditions that B would find sufficiently attractive to choose the factory over the farm if both alternatives were available without jeopardizing his family's only means of subsistence. Indeed, A might add, offering a job in sweatshop conditions might be the best he can do for B given his own precarious situation. While complicity is a wrongful element of the exchange in such circumstances, other considerations outweigh it, making A's involvement in the exchange justified on balance. ${ }^{37}$ Yet complicity calls for some response. Here, as Iris Marion Young argues, it seems inappropriate to blame A or demand compensation for his involvement in injustice, but appropriate to expect him to join others in political action aimed at more just structures and institutions. $^{38}$

While this response might suffice when complicity is unavoidable or justified by weighty countervailing considerations, it seems too lenient when no such extenuating circumstances obtain. Suppose A's appeal to his family's interests is not quite sincere. Then I believe shouldering the sort of political responsibility Young advocates is not enough. After

advantage taking is wrong, and even that it constitutes complicity, he doesn't elaborate on these claims.

${ }^{37}$ This is also why B shouldn't be blamed for their involvement in injustice in our cases. It follows from the causal approach to complicity that I have defended that both A and B are complicit. However, B's complicity is outweighed by more important considerations - their need for medical care or subsistence - and hence justified.

${ }^{38}$ Young, Responsibility for Justice. 
all, that responsibility is a very general one, incumbent on everyone involved in structural processes with unjust outcomes - that is, most or all of us. Agents who fail to avoid or justify complicity have, in addition to a general responsibility to promote justice in the future, a special obligation to compensate for their past or ongoing involvement in injustice. They ought to contribute to repairing the particular injustice they have taken advantage of. More concretely, A should contribute to improving access to health care in B's country in Clinical Trial, to reducing the economic vulnerability of small local farmers in Sweatshop Labor, and to fighting local racial and sexual discrimination in Domestic Work. The appropriate type and extent of compensation will vary between cases. However, requiring some compensation recognizes that complicity is a particular wrong committed by a particular agent against a particular group. ${ }^{39}$

\section{f) Exploitation and complicity}

I have claimed that exploitation and complicity are distinct moral categories, and I shall end this section by returning to that claim. A exploits B if the terms of their interaction are unfair to $\mathrm{B}$. A is complicit if A risks contributing to the structural injustice that leads B to interact. Unlike exploitation, complicity is a wrong primarily suffered by others than B, by victims of

\footnotetext{
${ }^{39}$ Young thinks that compensation claims, like blame and other backward looking responses targeting individuals, are inappropriate for addressing structural injustice because she considers individual causal contributions to such injustice too hard to ascertain. See Young, Responsibility for Justice, pp. 96, 109. I believe such responses are sometimes appropriate because I don't agree that ascertaining precise causal contributions is necessary for holding individuals accountable. While I recognize the value of Young's model of political responsibility, I don't think individuals should be spared blame and compensation as easily as she suggests - at least not in cases like those discussed in this paper.
} 
injustice who unlike B do not consent to or benefit from the exchange. The distinction between exploitation and complicity has generally been overlooked, perhaps because they tend to coexist in practice - as, indeed, I believe they do in our introductory cases. However, the two can come apart. We have seen that transactions can clearly be exploitative when there is no injustice to be complicit in, for instance if A secures an unfair deal by taking advantage of B's bad luck or imprudence.

Less obviously, transactions can involve complicity but no exploitation. In Concerned Neighbor $\mathrm{C}$ takes advantage of the discriminatory system that leaves B without better options. If $\mathrm{B}$ had fair access to education and the labor market she would be able to seek more attractive employment elsewhere. Yet the claim that C wrongfully exploits B seems strained because $\mathrm{C}$ does her best to benefit $\mathrm{B}$ : she simply cannot afford to pay more for the assistance she needs. The same goes for other equally constrained advantage-takers, such as the hard-pressed sweatshop manager just considered.

The charge of complicity seems less strained in such cases because complicity in injustice is not a wrong primarily suffered by an individual party to an exchange. While $\mathrm{C}$ doesn't treat B unfairly in Concerned Neighbor, she does risk contributing to the broader injustice framing their exchange. She gives herself reason to resist ending the discrimination that makes minority women willing to assist her at a price she can afford. She also sends the message that others too may profit from and neglect repairing that injustice. $\mathrm{C}$ is on balance justified in taking this risk, but her complicity requires her to join the collective pursuit of less unjust structures. $^{40}$

\footnotetext{
${ }^{40}$ Those who, unlike me, would call $\mathrm{C}$ an exploiter might agree that her conduct is on balance justified but creates political responsibilities. See Mayer, "Sweatshops, Exploitation, and Moral Responsibility,”pp. 615-16, 619.
} 


\section{Interference}

I have argued that analyzing two-party exchanges that take advantage of injustice in terms of complicity yields a different moral assessment than analyzing them in terms of exploitation. A further important difference emerges when we consider whether the state or other third parties may justifiably interfere with such advantage taking. Interfering with voluntary and mutually advantageous transactions in order to protect one of the parties from exploitation is not easy to justify. For such interference seems both harmful to and disrespectful of those one seeks to protect - harmful because it removes what they see as their best option, and disrespectful because it denies their exercise of autonomy in important self-regarding matters. ${ }^{41}$

Returning to Sweatshop Labor might elucidate these two points. Suppose the government in B's country, shocked by the exploitation of sweatshop workers, decides to ban sweatshops. Should B welcome this attempt to protect him from exploitation? On the contrary, it seems. Given that B has no other way of providing for himself and his family, losing the opportunity to work in the sweatshop severely sets back his (and his family's) interests. Also, by removing an option that B would have voluntarily chosen for B's own

\footnotetext{
${ }^{41}$ These are familiar enough points, commonly made both in general terms and (with certain variations) with reference to practical issues such as commercial surrogacy, prostitution, sweatshop labor, organ sales, and clinical research. See Wertheimer, Exploitation, pp. 115, 296-7; Nussbaum, “Whether from Reason or Prejudice,” pp. 721-22; Matt Zwolinski, “Sweatshops, Choice, and Exploitation,” Business Ethics Quarterly 17 (2007): 689-727; Radcliffe-Richards, "Nephrarious Goings On,” p. 377; and Wertheimer, Rethinking the Ethics of Clinical Research, pp. 240-44.
} 
sake, the government fails to treat B as somebody capable of deciding himself how to lead his life. It fails to treat B as an autonomous agent. ${ }^{42}$ Analogous points apply to the other cases.

So the case for an essentially libertarian stance on consensual and mutually advantageous exploitation might seem strong. However, there is a plausible response to that stance: what Wertheimer calls "the strategic argument" ${ }^{43}$ Strategic intervention seeks to secure a better (non-exploitative) option for B by removing a worse (exploitative) option. In Sweatshop Labor, for instance, the government might prevent A from hiring B on exploitative terms in order to make A hire B on more attractive terms. By banning sweatshops they might hope to make A offer B a higher wage and better working conditions: shorter days, longer breaks, a safer workplace, and so on. Such hopes may or may not be realistic; the success of strategic intervention depends on empirical facts that vary greatly between cases. ${ }^{44}$ But when successful such intervention neither harms nor disrespects B. It does remove an advantageous option from B's choice set, but only to replace it with a better one, an option that B much prefers but cannot secure on his own. ${ }^{45}$

One should distinguish between an individual and a collective version of the strategic argument. The latter advocates prohibiting a transaction between A and B in order to secure better terms for the class of B's rather than for B individually. The transaction, while beneficial to B, might weaken the bargaining position of others similarly placed. For instance, permitting B to work in sweatshop conditions might undercut the efforts of other B's to

\footnotetext{
${ }^{42}$ For an extensive analysis and endorsement of these two arguments in the case of sweatshops, see Zwolinski, "Sweatshops, Choice, and Exploitation."

${ }^{43}$ Wertheimer, Exploitation, pp. 300-5; Wertheimer, Rethinking the Ethics of Clinical Research, pp. 216-17.

${ }^{44}$ Wertheimer, Rethinking the Ethics of Clinical Research, p. 217.

${ }^{45}$ Wertheimer, Exploitation, p. 304.
} 
negotiate better working conditions for themselves. Interference then helps these other B's to secure better conditions. Often both individual and collective strategic reasons apply, because the individual B belongs to the larger class of B's that stand to gain from interference. But this isn't always the case. Prohibiting sweatshops might improve working conditions for most B's but leave some B's without employment. Justifying interference then requires balancing different interests against each other. ${ }^{46}$

Seeing things through the lens of complicity allows us to respond to the libertarian in a different (but not incompatible) way. A consensual and mutually advantageous transaction between $\mathrm{A}$ and $\mathrm{B}$ might be prohibited in order to prevent $\mathrm{A}$ from reinforcing the injustice that makes B agree to the transaction. Like the collective strategic argument, this argument appeals to the interests of parties beyond the actual transaction. However, it takes an even broader view of the interests at stake. The point isn't to advance the interests of B or the class of B's by influencing the terms of a particular transaction or transaction type. The point is to address structural injustices affecting many more people across many different forms of interaction. It is to advance the interests of these larger social segments that $\mathrm{A}$ is prevented from taking advantage of and thereby reinforcing structural injustice when interacting with B.

The complicity argument (as we might call it) shares an attractive feature with the strategic argument: it doesn't deny B's capacity to make his or her own choices. The reason for interference isn't to protect B from being taken advantage of regardless of B's own view on the matter. Instead, the reason is to protect others with a stake in the exchange.

\footnotetext{
${ }^{46}$ There are in principle as many ways to approach such balancing as there are basic conceptions of distributive justice. A utilitarian approach would recommend interference if it maximizes aggregate net benefit, a Rawls-inspired maximin approach would recommend interference if it advances the interest of the worst-off better than non-interference, and so on. Which approach to embrace is too large and thorny an issue to be treated systematically here.
} 
The complicity argument admittedly has important limitations. First, it rests on hard-to-prove empirical assumptions. Whether interference is justified depends on what the effects on structural injustices will be, and that may obviously be difficult to tell. Now the complicity argument doesn't in principle differ from the strategic argument in this respect, but there may be a considerable difference in degree. The complicity argument may look more utopian because the desired effects are likely to be more distant and uncertain. Second, as with many collective strategic interventions, difficult trade-offs between interests are needed. Since we are dealing with mutually advantageous transactions, interference will harm both A and (barring strategic considerations) B. These harms are no less real because they are incurred in the course of rectifying structural injustices. The complicity argument might look not only utopian, but dangerously so. However, it isn't always unreasonable to prioritize large-scale social change over individual interests. ${ }^{47}$

It is worth stressing that there is no conflict between the complicity argument and the strategic argument. Both may support interfering with one and the same transaction. That is, interference may aim at both securing better terms for B (or the class of B's) and addressing the broader injustice that make B (or the class of B's) willing to settle for less. The complicity argument might tip the scales in favor of interfering when there are strategic reasons for, but other reasons against, interference. But it shouldn't be ruled out that it might carry the day even when strategic reasons don't apply.

\section{Conclusion}

\footnotetext{
${ }^{47}$ Again, how competing interests should be weighed raises fundamental questions about distributive justice that are beyond the scope of this paper.
} 
Deep structural injustices form part of the backdrop against which contemporary social and economic life plays out. It is no exaggeration to say that many exchanges take advantage of injustice. Does that fact affect their moral legitimacy? I have argued that it does, but not for the reason typically proposed. While it is true that many such exchanges are exploitative, it isn't the background injustice that makes them so. The relevance of background injustices to the ethics of individual exchanges is better understood in terms of complicity. To take advantage of structural injustices is to risk contributing to their perpetuation - even when those taken advantage of consent to and benefit from the exchange, and even when they aren't exploited. Complicity in injustice is often a comparatively minor wrong, and difficult to avoid, but it is still a wrong requiring justification or compensation. I have also suggested that recognizing complicity as a distinct wrong alongside that of exploitation makes it easier though hardly trivial - to justify third party interference with exchanges that prey on structural injustice. My analysis has admittedly focused rather narrowly on one type of human interaction. Yet I hope it might contribute to the much broader task of clarifying how we should respond, individually and institutionally, to the pervasive injustices that surround us. ${ }^{48}$

\footnotetext{
${ }^{48}$ I am grateful to Martin Andersson and two anonymous reviewers for this journal for helpful comments on earlier versions of this paper.
} 